\title{
APLIKASI STANDAR AWS UNTUK MENENTUKAN ACCEPTANCE CRITERIA PADA PENGELASAN SMAW MENGGUNAKAN NONDESTRUCTIVE TEST-ULTRASONIC TEST
}

Tito Endramawan'1, Agus Sifa²

\author{
Politeknik Negeri Indramayu ${ }^{1,2}$ \\ J. Lohbener Lama No. 08 Lohbener - Indramayu ${ }^{1,2}$ \\ titoendramawan@gmail.com¹, agus.sifa86@gmail.com²
}

\begin{abstract}
ABSTRAK
Tujuan penelitian ini adalah menentukan spesimen uji tersebut bisa diterima berdasarkan aceptance criteria AWS. Penelitian ini menggunakan material mild steel dengan nilai kekerasan $135 \mathrm{HVN}$ dengan ukuran $30 \mathrm{~cm}$ x $20 \mathrm{~cm}$ x 1,2 cm yang disambungkan dengan proses pengelasan SMAW posisi 3G butt joint dengan elektroda rooting LB 52U diameter 2,6 mm menggunakan arus 70 Amper dan tegangan 380 volt, sedangkan untuk filler menggunakan elektroda LB 5218 diameter 3,2 mm dengan arus 80 Amper dan tegangan 380 volt. Metode untuk menginspeksi hasil lasan menggunakan Non Destructive Test Ultrasonic Testing (NDTUT) dengan blok standar V1 dan V2 sebagai reference block untuk proses kalibrasi. Probe yang digunakan berupa probe sudut $70^{\circ}$ dengan frekuensi $4 \mathrm{MHz}$ merk karl deutch sesuai dengan tabel 6.7 yang hasil pengelasannya merujuk tabel 6.2 tentang UT Acceptance-Rejection Criteria pada AWS D1.1/D1.1M:2010 menurut class indication. Hasil pengujian menunjukkan bahwa base material dari baja karbon rendah dengan kandungan 0,193\% dan 98,713\% Fe dengan nilai kekerasan rata-rata 135,2 VHN. Hasil pengujian pada ketiga spesimen diatas menunjukkan bahwa class untuk dincontinuity di kategorikan pada class D berdasarkan nilai dari frekuensi gelombang (d) yang lebih dari $+8 \mathrm{~dB}$ sehingga discontinuity yang ada harus di accepted tanpa melihat panjang atau lokasi-nya pada lasan. Apabila ada indikasi defect yang rejected maka tindak lanjutnya adalah dengan melakukan perbaikan dengan cara gouging atau digerinda pada bagian yang mengindikasikan adanya cacat tersebut dan kemudian dilas ulang.
\end{abstract}

Kata Kunci: Standar AWS, NDT-UT, SMAW.

\section{PENDAHULUAN}

Indonesia adalah negara besar yang memiliki jumlah pertumbuhan penduduk yang cukup signifikan yaitu terbesar keempat di dunia (setelah Republik Rakyat Tiongkok, India dan Amerika Serikat). Berdasarkan pada proyeksi pemerintah pada tahun 2014, jumlah penduduk Indonesia akan meningkat dari 237,6 juta orang di 2010 menjadi 271,1 juta orang di 2020 dan menjadi 305,6 juta orang di 2035 [1].

Disamping itu, masih berdasarkan data Badan Pusat Statistik, jumlah kendaraan yang beroperasi aktif di seluruh Indonesia pada 2013 adalah 104,118 juta unit, Populasi jumlah kendaraan terbanyak adalah sepeda motor dengan jumlah 84,732 juta unit di seluruh Indonesia, Jumlah terbesar kedua adalah mobil penumpang dengan 11,48 juta unit, Populasi mobil barang (truk, pikap, dan lainnya) adalah 5,615 juta unit dan populasi mobil penumpang adalah 2,286 juta unit[2].

Dengan adanya jumlah penduduk yang besar dan kenaikan jumlah kendaraan maka kebutuhan akan sumber daya mineral, minyak dan gas akan meningkat. Dalam hal ini pemerintah melalui badan usaha milik negaranya, pertamina terus Mengupayakan untuk mencukupi kebutuhan tersebut. Berdasarkan data dari pertamina kebutuhan masyarakat Indonesia akan bahan bakar minyak mencapai 1,6 juta barel oil perhari (BOPD), sedangkan total produksi minyak nasional berada pada level 
831 ribu barel minyak per hari (MBOPD).

Oleh karena itu pertamina berencana mencari ladang minyak baru terutama di Indonesia bagian timur [3].

Dalam pembukaan lahan baru untuk mencari sumber daya tersebut diperlu-kan sarana dan prasarana yang baru salah satunya bagian perpipaan dan tempat penampungan minyak dan gas. Pembuatan pipa dan tempat penampungan minyak dan gas akan behubungan dengan proses pengelasan.

Proses pengelasan beberapa jenis diantaranya adalah Shielded Metal Arc welding (SMAW) Gas Metal Arc Welding (GMAW), Gas Tungsten Arc Welding (GTAW), Flux-cored Arc Welding (FCAW), dan Submerged Arc Welding (SAW). Perkembangan pengelasan semakin waktu semakin maju dengan ditemukanya pengelasan menggunakan robot dengan tujuan lebih cepat dan hasil yang lebih baik.

Teknologi pengelasan pada saat ini mengalami perkembangan cukup maju dengan berbagai metode baru yang telah ditemukan baik yang menggunakan konvensional maupun yang otomatis. Pengelasan memiliki banyak keunggulan, akan tetapi dalam proses pengelasan logam hasilnya tidak selalu bagus, hal ini terjadi dipengaruhi oleh banyak faktor baik yang sengaja maupun yang tidak disengaja. Untuk menangani hal tersebut maka diperlukan adanya inspeksi hasil pengelasan agar sesuai dengan keinginan dan aman untuk digunakan.

Metode untuk menginspeksi hasil pengelasan salah satunya adalah dengan uji Non Destructive Test (NDT). Uji tidak merusak (NDT) adalah teknik analisis yang digunakan dalam ilmu pengetahuan dan industri untuk mengevaluasi sifat dari komponen, material atau sistem tanpa menyebabkan kerusakan. Karena NDT tidak mengubah komponen yang diperiksa, metode ini merupakan teknik yang dapat menghemat uang dan waktu dalam evaluasi produk, pemecahan masalah, dan penelitian. Yang termasuk uji NDT adalah uji ultrasonik, magnetik-partikel, penetran cair, radiografi, dan pengujian $e d d y$.

Dalam pengujian ini, metode yang digunakan adalah Ultrasonic Testing (UT) yaitu pengujian yang dilakukan untuk mengetahui cacat permukaan (Surface) dan permukaan bawah (sub-surface) suatu komponen dari material. Dengan menggunakan prinsip gelombang ultrasonik yang dipantulkan dan dibiaskan oleh permukaan batas antara dua bahan yang berbeda. Dari sifat pantulan tersebut dapat ditentukan tebal bahan, lokasi cacat serta ukuran cacat. Cacat yang mudah dideteksi oleh gelombang ultrasonik adalah cacat yang tegak lurus terhadap arah rambatan gelombang karena cacat tersebut mudah memantulkan kembali gelombang untuk diterima oleh probe.

Tujuan dari penelitian ini adalah menentukan acceptance criteria pada hasil pengelasan SMAW dengan menggunakan Non Destructive Test Ultrasonic Testing (NDT UT) berdasarkan standar American Welding Society (AWS).

\section{TINJAUAN PUSTAKA}

Proses pengelasan SMAW ini termasuk kedalam kelompok proses pengelasan arc welding, yang didalamnya termasuk pengelasan Gas Tungten Arc Welding dan Gas metal Arc Melding. pada beberepa penelitian sebelumnya menyatakan bahwa teknik pengelasan kelompok arc welding ini dapat diteliti hasil pengelasanya menggunakan ultrasonic testing (Tiago and Carlos, 2014). Proses penilaian yang dikembangkan menggunakan metode ultrasonic dari tranduser yang dilakukan pada daerah sambungan pengelasan dengan teknik kontak langsung.

Menurut Rafael Martinez, dkk., menjelaskan tentang metodologi untuk kualifikasi dan demontrasi teknik uji ultrasonik untuk menentukan hasil sambungan las pada bejana tekan. Bejana tekan ini terbuat dari plat baja tempa yang disambung las dengan bentuk dan ukuran yang telah disesuaikan. Proses inspeksi 
dilakukan hanya dari satu bagian saja yaitu bagian luar dari sambungan las[7].

Tabatabaeipour dan Honarvar (2010) tentang uji ultrasonik dengan membandingkan hasil pengelasan SMAW dan GTAW pada baja AISI 316L. Karakter austenitik terbagi dalam distribusi orientasi butir dan anisotropi menunjukan bahwa pada spesimen GTAW lebih isotropik dibandingkan SMAW untuk orientasi butiran. Hasil B-scan menunjukan inspeksi SMAW lebih mudah daripada proses GTAW[8].

Berdasarkan Habib Alavi dan Sandip (2015), aplikasi ultrasonik untuk proses konvensional meliputi pengecoran dan pengelasan. Mereka melaporkan gelombang ultrasonik pada baja austenitic stainless steel (AISI 316) dengan sistem investigasi pengaruh gelombang ultrasonik frekuensi $20 \mathrm{kHz}$ pada mikrostruktur material selama proses pengelasan. Jiromaru dkk., tentang complex vibration system yang mana ultrasonic welding secara efektif diterapkan untuk berbagai jenis spesimen termasuk spesimen logam yang sama maupun untuk spesimen dengan logam yang berbeda[9].

Levesque, dkk., (2016), tentang inspeksi ketebalan sambungan las pada menggunakan laser ultrasonik SAFT. Mendeteksi dari defect pada sambungan butt pada pengelasan dituntut untuk mengurangi biaya dan waktu pengerjaan ulang. Spesimen yang digunakan dari baja dengan ketebalan $25 \mathrm{~mm}$ dan $50 \mathrm{~mm}[10]$.

Sifa. A, dkk., tentang inspeksi hasil pengelasan pada hasil spot welding menggunakan ultrasonik tes, probe dengan frekuensi $4 \mathrm{MHz}$ dengan kuplan oli serta dengan menggunakan teknik $6 \mathrm{~dB}$ drop dengan kecepatan rambat gelombang pada baja sebesar $2267 \mathrm{~m} / \mathrm{s}[12]$.

\section{METODE PENELITIAN}

Pada penelitian ini menggunakan material dari plat baja karbon dengan ukuran $30 \mathrm{~cm} \times 20 \mathrm{~cm} \times 1,2 \mathrm{~cm}$ yang dibevel pada $30^{\circ}$ pada panjang $30 \mathrm{~cm}$ yang kemudian dilas SMAW posisi 3G. Mesin las yang digunakan merk maxstar 200 dengan parameter pengelasan berupa elektroda rooting LB 52U diameter 2,6 mm sedangkan filler menggunakan elektroda LB 5218 diameter 3,2 $\mathrm{mm}$ dengan arus 80 Amper dan tegangan 380 volt[11].

Pengujian komposisi menggunakan alat uji spektrometer dengan mesin uji type ARL 3460 Optical Emission Spectrometer dengan ukuran spesimen $50 \mathrm{~mm}$ x $25 \mathrm{~mm}$ x $10 \mathrm{~mm}$.

Pengujian keras base material dengan alat uji innovatest tipe verzus 700AS metode vickers dengan pembebanan 20 Kgf dan waktu indentasi 10 detik. Berdasarkan ASTM E-384 menetapkan sudut indentor intan sebesar $136^{\circ}$ (gambar $1)$.

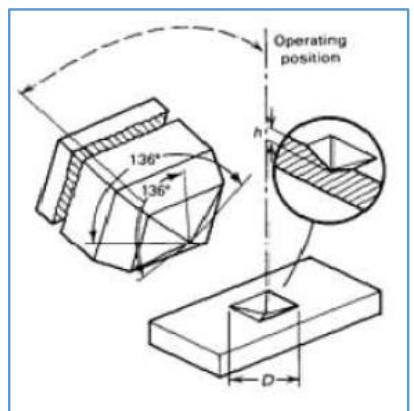

Gambar 1. Uji Kekerasan Vickers[5]

Penentuan nilai kekerasan vickers dengan menggunakan persamaan:

$$
H V=\frac{1.8544 P}{d^{2}}
$$

\section{Non Destructive Test Ultrasonic Testing}

Langkah-langkah kalibrasi alat UT

1. Nyalakan pesawat UT, hubungkan probe sudut ke pesawat melalui kabel MPKL

2. Masuk menu,masuk jenis probe dan pilih Angle dan masukan sudut $70^{\circ}$.

3. Kembali ke menu utama, pilih Two Point Calibration, pada path 1 input nilai $25 \mathrm{~mm}$ dan path 2 input $100 \mathrm{~mm}$, selanjutnya pilih next.

4. Untuk menentukan path 1 dan path 2 gunakan blok V2 dan arahkan probe pada radius $25 \mathrm{~mm}$.

5. Cari nilai amplitudo tertinggi, kemudian tentukan pulsa pertama ditentukan 
sebagai path 1 dan pulsa ke dua sebagai path 2 lalu tekan OK.

6. Cek hasil kalibrasi dengan meletakan probe pada radius $100 \mathrm{~mm}$ dan diatas celah $30 \mathrm{~mm}$ jika indikasi muncul pada skala 10 maka kalibrasi sudah benar.

7. Pada menu awal, pilih Material Thickness, tentukan ketebalan sesuai tebal material yang akan diuji.

\section{Metode penentuan acceptance criteria}

1. Ukur dimensi benda uji berupa panjang, lebar dan tebal

2. Cek permukaan hasil pengelasan dengan metode visual

3. Kalibrasi alat menggunakan probe normal untuk mengecek cacat laminasi pada base material

4. Menentukan probe yang digunakan dengan mengacu pada tabel 6.7 AWS D1.1[6]

5. Tentukan range, $\mathrm{R}>$ tebal benda

6. Tentukan scanning level (SL) menurut tabel 6.2 AWS D1.1

7. Kalibrasi probe sesuai dengan range yang digunakan

8. Cek sensitivity pada V1 diatas lubang $1,5 \mathrm{~mm}$, cari maksimal pulsa 40$60 \% \mathrm{FSH}$

- Catat gain ref $(b)=\ldots \ldots . . d B$

- Gain operasi $=b+\mathrm{SL}=\ldots . . \mathrm{dB}$

9. Analisa cacat

- Cacat di leg $\mathrm{I}<\frac{t}{\cos \beta} \times \frac{10}{R}$

- Cacat di leg Ii $>\frac{t}{\cos \beta} \times \frac{10}{R}$ dan $<\frac{2 t}{\cos \beta} \times \frac{10}{R}$

10. Scaning cacat

- Jika ditemukan cacat pastikan pulsa di maksimal $40-60 \%$ FSH, didapat So dan Xo.

- So = Skala layar pulsa layar (40$60 \%$ ) cacat gain (a).

- Xo = jarak dari titik tengah lasan ke titik indeks.

- Untuk mencari S1 dan X1 probe dimajukan s/d 10\% FSH.

- Untuk mencari S2 dan X2 probe dimundurkan s/d 10\% FSH.

- Untuk L (panjang cacat) posisikan probe di pulsa $100 \%$ geser probe ke kiri dan kanan sampai pulsa 50\% (ujung cacat)

11. Menentukan attenuation factor (c). $S_{0}(\operatorname{Inc})=\frac{S_{0}(\mathrm{~mm})}{25,4}=\cdots$ inchi

12. Menentukan indication rating $(\mathrm{d})$.

$-d=a-b-c$

-Jika d sudah didapat referensi tabel 6.2 AWS D1.1, untuk menentukan kelas cacat

13. Jika kelas cacat sudah ditentukan, maka didapat pula Acc / Reject untuk cacat tersebut dengan melihat tabel 6.2 AWS D1.1.

14. Untuk scaning cacat berikutnya, kembalikan gain ke gain operasi (gop) terlebih dahulu sebelum di scaning.

\section{Penggolongan kelas discontinuity}

1. Class A (large discontinuities) yaitu beberapa indikasi pada kategori ini harus di rejected (berapapun panjangnya), $d=$ $+5 \mathrm{~dB}$ dan lebih rendah.

2. Class B (medium discontinuities) yaitu beberapa indikasi dalam kategori ini lebih panjang dari $3 / 4$ in $(20 \mathrm{~mm})$ harus di rejected, $\mathrm{d}=+6 \mathrm{~dB}$.

3. Class $\mathrm{C}$ (small discontinuities) yaitu beberapa indikasi dalam kategori ini mempunyai panjang dari 2 in $(50 \mathrm{~mm})$ harus di rejected, $\mathrm{d}=+7 \mathrm{~dB}$.

4. Class D (minor discontinuities) yaitu beberapa indikasi dalam kategori ini harus di accepted tanpa memperhatikan panjang dan lokasi pada pengelasan $\mathrm{d}=$ $+8 \mathrm{~dB}$.

\section{HASIL DAN PEMBAHASAN}

Uji komposisi

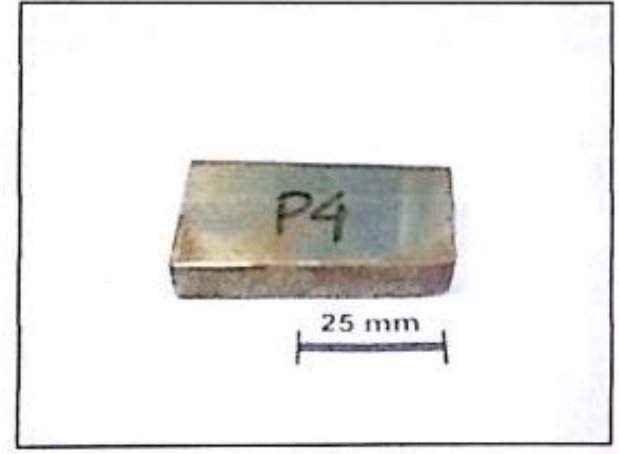

Gambar 2. Spesimen Uji spektrometri 
Pengujian komposisi untuk base material (gambar 2) dilakukan dengan menggunakan alat uji spektrometri merk ARL 3460 pada kelembapan 59\% dan suhu ruangan $23^{\circ} \mathrm{C}$ dengan hasil sebagai berikut:

Tabel 1. Komposisi base material

\begin{tabular}{|c|c|c|}
\hline No & Unsur / Element & Nilai (\%) \\
\hline 1 & Carbon & 0,212 \\
\hline 2 & Silicon & 0,189 \\
\hline 3 & Sulfur & 0,014 \\
\hline 4 & Phosporus & 0,021 \\
\hline 5 & Manganese & 0,716 \\
\hline 6 & Nickel & 0,02 \\
\hline 7 & Chromium & 0,06 \\
\hline 8 & Molybdenum & 0,005 \\
\hline 9 & Ferro/iron & 98,713 \\
\hline
\end{tabular}

Berdasarkan tabel 1 di atas, hasil pengujian komposisi base material dapat disimpulkan bahwa material tersebut mengandung unsur karbon 0,193\% berarti termasuk Baja Karbon Rendah[4].

\section{Uji Kekerasan}

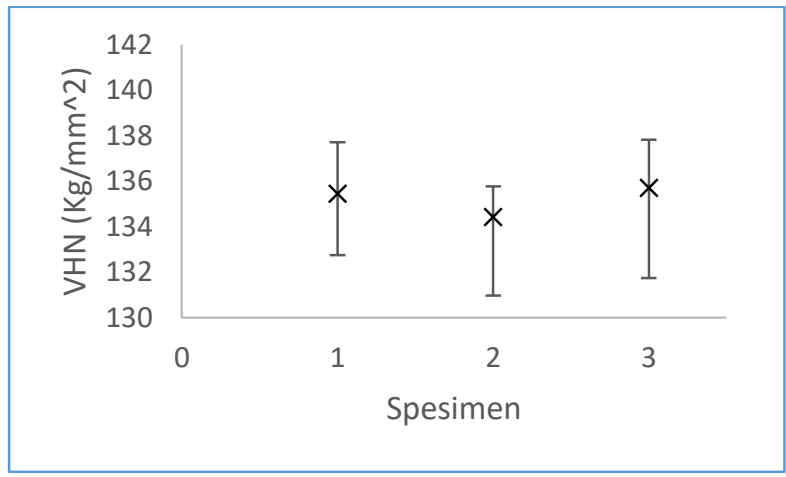

Gambar 3. Hasil uji kekerasan

Berdasarkan gambar 3 menunjukkan nilai kekerasan rata-rata dari tiga sampel yang diuji adalah 135,2 VHN dengan nilai kekerasan minimum 130,9 VHN dan kekerasan maksimum 137,7 VHN.

\section{Uji NDT Ultrasonik}

Tabel 2. Uji UT Spesimen 1

\begin{tabular}{|c|c|c|c|c|c|c|c|c|}
\hline \multirow{2}{*}{ 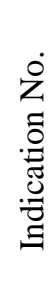 } & $\circ \vec{A}$ & \multicolumn{4}{|c|}{$\begin{array}{l}\text { Position, Location } \\
\text { and Size }(\mathrm{mm})\end{array}$} & \multicolumn{3}{|c|}{$\begin{array}{c}\text { Discontinuit } \\
\mathrm{y}\end{array}$} \\
\hline & 总青 & $\mathrm{L}$ & 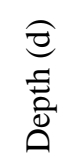 & $\begin{array}{l}\sqrt{x} \\
\infty \\
0 \\
2\end{array}$ & 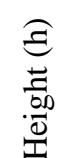 & $\underset{\Leftrightarrow}{\stackrel{D}{\natural}}$ & $\begin{array}{l}\vec{z} \\
\stackrel{0}{0} \\
\overline{0} \\
\frac{\pi}{\alpha}\end{array}$ & 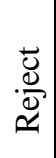 \\
\hline & & & & & & & & \\
\hline 1 & 14,5 & 5 & 10,5 & 3,8 & 28,8 & incl & $\sqrt{ }$ & \\
\hline 2 & 17,1 & 9 & 10 & 0,5 & 27,5 & incl & $\sqrt{ }$ & \\
\hline 3 & 19,2 & 6 & 10 & 2,5 & 27,5 & incl & $\sqrt{ }$ & \\
\hline
\end{tabular}

Berdasarkan tabel 2 diatas, pengujian ultrasonik pada spesimen I, ditemukan adanya indikasi discontinuity maka sinyal menunjukan bahwa face I terdapat dua indikasi cacat pada kedalaman $9 \mathrm{~mm}$ dan $11 \mathrm{~mm}$ dengan panjang $10 \mathrm{~mm}$ dan $12 \mathrm{~mm}$ sedangkkan jarak dari tengah lasan adalah 1,8 $\mathrm{mm}$ dan 2,6 $\mathrm{mm}$ dan pada face II terdapat dua indikasi cacat pada kedalaman $11 \mathrm{~mm}$ dan 8,5 $\mathrm{mm}$ dengan panjang $16 \mathrm{~mm}$ dan $10 \mathrm{~mm}$ serta jarak dari tengah lasan adalah 1,3 $\mathrm{mm}$ dan $1,4 \mathrm{~mm}$. Setelah dilakukan acceptance criteria dengan merujuk AWS D1.1 ditetapkan bahwa spesimen 2 ini dinyatakan accepted karena masuk pada kelas D.

Tabel 3. Uji UT Spesimen 2

\begin{tabular}{|c|c|c|c|c|c|c|c|c|}
\hline \multirow[b]{2}{*}{ 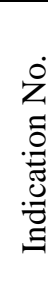 } & \multirow{2}{*}{ 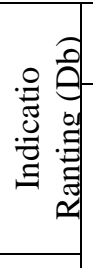 } & \multicolumn{4}{|c|}{$\begin{array}{l}\text { Position, Location } \\
\text { and Size (mm) }\end{array}$} & \multicolumn{3}{|c|}{$\begin{array}{c}\text { Discontinuit } \\
\mathrm{y}\end{array}$} \\
\hline & & & 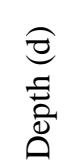 & $\begin{array}{l}\underset{\otimes}{\otimes} \\
\stackrel{0}{2}\end{array}$ & 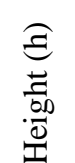 & 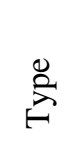 & 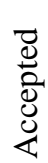 & $\begin{array}{l}\frac{\bar{u}}{2} \\
\simeq\end{array}$ \\
\hline 1 & 14.5 & 5 & 10.5 & 3.8 & 288 & incl & $\sqrt{ }$ & \\
\hline 2 & 17,1 & 9 & 10 & 0,5 & 27,5 & incl & $\sqrt{ }$ & \\
\hline 3 & 19,2 & 6 & 10 & 2,5 & 27,5 & incl & $\sqrt{ }$ & \\
\hline
\end{tabular}

Dari tabel 3, hasil pengujin ultrasonik tes terdapat lima indikasi discontinuity pada kedalaman 10,5 mm, 10 $\mathrm{mm}$ dan $10 \mathrm{~mm}$ dengan panjang $5 \mathrm{~mm}, 9$ $\mathrm{mm}$ dan $6 \mathrm{~mm}$ sedangkkan Jarak dari tengah lasan adalah $3,8 \mathrm{~mm}, 0,5 \mathrm{~mm}$ dan 2,5 $\mathrm{mm}$. Setelah dilakukan acceptance criteria dengan merujuk AWS D1.1 
ditetapkan bahwa spesimen 2 ini dinyatakan accepted karena masuk pada kelas D.

Tabel 4. Uji UT Spesimen 3

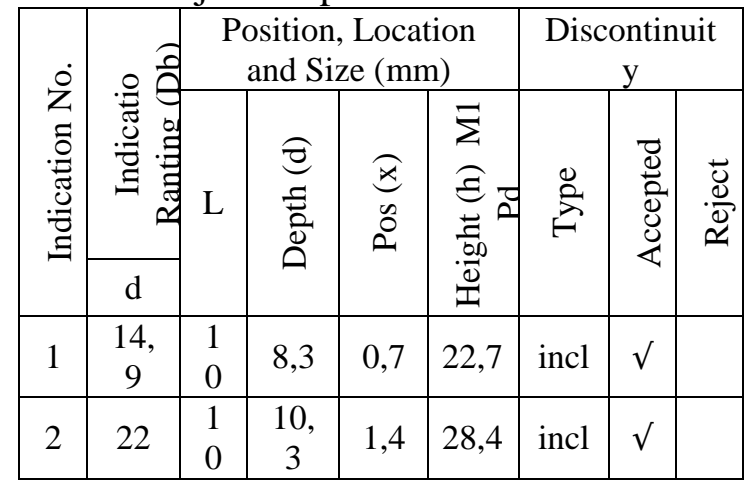

Dari hasil pengujin ultrasonik tes maka sinyal menunjukan bahwa terdapat dua indikasi cacat pada kedalaman $8,3 \mathrm{~mm}$ dan 10,3 $\mathrm{mm}$ dengan panjang $10 \mathrm{~mm}$ sedangkan Jarak dari tengah lasan adalah 1,4 $\mathrm{mm}$ dan $0,7 \mathrm{~mm}$. Setelah dilakukan acceptance criteria dengan merujuk AWS D1.1 ditetapkan bahwa spesimen 3 ini dinyatakan accepted karena masuk pada kelas D.

\section{KESIMPULAN}

Berdasarkan pengujian yang telah dilakukan, didapatkan beberapa kesimpulan sebagai berikut:

1. Komposisi base material mengandung 0,193\%C dan $98,713 \% \mathrm{Fe}$ sehingga termasuk baja karbon rendah.

2. Nilai kekerasan rata-rata dari base material adalah 135,2 VHN

3. Hasil pengujian pada ketiga spesimen diatas menunjukkan bahwa class untuk dincontinuity di kategorikan pada class D berdasarkan nilai dari frekuensi gelombang (d) yang lebih dari $8 \mathrm{~dB}$ sehingga discontinuity yang ada harus di accepted tanpa melihat panjang atau lokasi-nya pada lasan.

\section{DAFTAR PUSTAKA}

[1]. Badan Pusat Statistik. 2017. Statistik Indonesia.

https://www.bps.go.id.
Diakses pada tanggal 10 Agustus 2017.

[2]. Badan Pusat Statistik. 2017. Jumlah kendaraan bermotor. https:// www.bps.go.id/dataset.

Diakses pada tanggal 10 Agustus 2017.

[3]. Pertamina.2016. Mengaji strategi penuhi kebutuhan energi nasional. http:// www.pertamina.com. Diakses pada tanggal 12 Juni 2017.

[4]. Wiryosumarto dan Okumura (1991). Teknologi pengelasan logam Jakartab : Pradnya Paramita.

[5]. Mechanical Testing and Evaluation Volume 8 of the ASM Handbook Committee (2000).

[6]. American Welding Society (AWS) D1 Committee, "Structural Welding Code - Steel", American National Standards Institute (2010).

[7]. Rafael Martínez, et.al., "Ultrasonic inspections in the fabrication of the ITER vacuum vessel sectors", Fusion Engineering and Design 88 (2013) 21552159.

[8]. Tabatabaeipour, and F. Honarvar, "A comparative evaluation of ultrasonic testing of AISI 316L welds made by shielded metal arc welding and gas tungsten arc welding processes", Journal of Materials Processing Technology $210 \quad$ (2010) 1043-1050.

[9]. Habib Alavi, Sandip P. Harimkar, "Melt expulsion during ultrasonic vibration-assisted laser surface processing of austenitic stainless steel", Ultrasonics 59 (2015) 21-30. 
[10]. Levesque, et.al., "Inspection of thick welded joints using laserultrasonic SAFT", Ultrasonics 69 (2016) 236242.

[11]. T. Endramawan, Emin H., Felix D., Yuliana P., "Aplikasi Non Destructive Test Penetrant Testing (Ndt-Pt) Untuk Analisis Hasil Pengelasan Smaw 3g Butt Joint”. Jurnal Teknologi Terapan, Volume 3, Nomor 2.

[12]. A.Sifa, T. Endramawan, and Badruzzaman. "Identification of the Quality Spot Welding used Non Destructive TestUltrasonic Testing: (Effect of Welding Time)". IOP Conference Series: Materials Science and Engineering, Volume 180, Number 1. 